\title{
Economia Política e EducaÇão
}

São conhecidas as relaçóes que vinculam o plano da economia e da política às questôes de natureza educacional. A famosa frase atribuída a Francis Bacon: "saber é poder", não era apenas uma expressão simbólica destituída de sentido fático; antes, buscava expressar a maneira pela qual o poder se vale do saber e vice-versa, animando (e mesmo justificando) a incessante busca de subordinação dos processos de produção, circulação e distribuiçáo do conhecimento a seus interesses, que por sua vez intentam representar os interesses que frequentam o plano da produção econômica.

Em registro estritamente acadêmico, trata-se de da mútua referenciação que se estabelece entre as teorizaçóes que frequentam os campos da produção material e da formação pedagógica. O movimento que estabelece, contemporaneamente, vínculos mais estreitos e perceptíveis entre esses dois campos radica no processo de mudanças qualitativas nas bases materiais do modo de produção deflagradas a partir do fim das guerras mundiais, motivando a reconfiguração da ordem política internacional e inaugurando um processo de revisão de políticas, sistemas e processos educacionais na esfera dos Estados nacionais. A reorganização dos modelos produtivos e as consequentes alterações requeridas em termos de perfis profissionais e capacidades para o trabalho impóem ao campo da educação a busca de correspondência curricular e epistêmica. Daí o papel cada vez mais influente e contundente dos organismos multilaterais, comprometidos com a nova ordem econômica e política mundial, na direção de propor tais revisóes aos sistemas e às políticas de formação, agora em chave internacionalista.

Ocorre que os sistemas educativos nacionais estiveram preparados para processos formativos voltados às matrizes culturais e aos desafios econômicos do nacional, e agora se vêm premidos por mudanças políticoeconômicas e socioculturais que se póem em torno da dimensão global, de uma emergente Sociedade do Conhecimento, de um mundo em interação cada vez mais midiatizada e virtualizada. E, nesse diapasão, cabia também criar as fórmulas simbólicas que vetorizassem os caminhos de desenvolvimento dos sistemas educativos. Grassam, então, modelos de expansão baseados, entre outras, em estratégias de privatização, mercantilização e 
financeirização das instituiçôes de educação, ajustando-as aos modelos institucionais que adotam padróes de gestão, competitividade, produtividade e performance requeridos pela economia de mercado.

A proposta deste Dossiê Temático de EccoS, que ora publicamos, tem o objetivo de propor o debate que articula economia política e educação, campos cada vez mais interdependentes em razão dos requisitos de formação que, do âmbito da produção econômica, orientam a formação e a pesquisa desenvolvida nos sistemas educacionais. E, desse modo, oportuniza o debate de temas os mais diversos como os impactos da regulação transnacional; o papel do Estado contemporâneo; as relações entre educação e desenvolvimento; as implicaçóes econômicas da pesquisa, da ciência e da tecnologia; as condiçôes de produção do trabalho docente; a geopolítica e a economia do conhecimento; a relevância da educação em tempos de sociedade do conhecimento.

Foram essas as abordagens que se procurou estabelecer e harmonizar a partir da expressiva demanda de contribuiçôes, na forma de artigos de investigação e ensaios teóricos, recebidas ao longo de cinco meses desde a publicação da chamada pública.

O primeiro artigo do Dossiê, Para além das métricas simplistas na pesquisa educativa. As liçóes da continua relevância e impacto freiriano, de Gustavo Enrique Fischman, Sandra Regina Sales e Esther do Lago e Pretti, constitui uma análise crítica do modo como é atribuído o fator de impacto às revistas do campo das Ciências Sociais e, mais especificamente, do campo da educação. Os autores defendem que os processos de avaliação baseados nesse indicador produzem distorçôes que eles denominam de simplimetrificação, já que pretendem mensurar a qualidade das pesquisas sem avaliar sua relevância, fazendo-o apenas indiretamente no uso da quantidade de artigos publicados em periódicos científicos com alto fator de impacto, ou, no caso do Brasil, bem ranqueados no Qualis.

No segundo artigo, El Paraguay y la acreditación de carreras de grado en el Mercosur, de Gladys Beatriz Barreyro e Gabriella de Camargo Hizume, analisam os processos que levaram à implantação da avaliação da educação superior no Paraguay, mostrando como é criada e recriada uma política global de avaliação. Resultado de uma pesquisa bibliográfica, documental e de campo, as autoras discutem a elaboração e desenvolvimento dos processos de avaliação e acreditação. 
Capital fictício e educação no Brasil: um estudo sobre a lógica contemporânea da privatização é o terceiro artigo, escrito por Luciana Sardenha Galzerano e Lalo Watanabe Minto. O objetivo do estudo é apresentar algumas das tendências que têm caracterizado a privatização da educação no contexto da crescente mercantilização e vinculaçáo com as formas de capital fictício. A partir de um referencial teórico marxista, os autores consideram que a predominância da financeirização em grande parte do setor educacional brasileiro representa o desenvolvimento da lógica da acumulação capitalista contemporânea.

O quarto artigo, Governar pela autonomia: Universidade, Inovação e Capitalismo Cognitivo, da lavra de Murilo Duarte Costa Corrêa, João Guilherme Pereira Chaves e Diego Petyk de Sousa, tem por objetivo descrever como um paradigma de governo neoliberal é internalizado pelas recentes transformaçóes na concepção de autonomia universitária. A pesquisa, de caráter bibliográfico, sugere que as transformaçóes da autonomia universitária acompanham a dinâmica do capitalismo global que promove o deslocamento de uma economia industrial à de um capitalismo cognitivo ou imaterial. Nesse contexto, a autonomia universitária é tensionada como forma de governo ajustada ao modelo do capitalismo cognitivo e à abstração financeira, tornando-se o elemento central de um paradigma de governo neoliberal emergente.

Maria Carolina Pires de Andrade e Bruno Gawryszewski, em Desventuras da educação brasileira e as 'reformas' atuais: educar para a produtividade do trabalho, abordam as 'reformas' instituídas com a Base Nacional Comum Curricular (BNCC) e o Novo Ensino Médio (NEM). Pretendem compreender a simultaneidade das reformas educacionais com tantas outras em curso. Trata-se de uma análise teórica que busca um diálogo entre o texto legal das 'reformas' e o dos relatórios de organismos internacionais com a teoria do valor-trabalho de Marx, mediado por referenciais que tratam das particularidades do capitalismo dependente, como Florestan Fernandes. Os autores concluem que o conteúdo das propostas educacionais contradiz o discurso que as legitima, apresentando ressonância nas diretivas dos organismos internacionais; essas reformas atendem às necessidades candentes das fraçóes da burguesia brasileira que vem operando reformas na estrutura e na superestrutura do bloco histórico com vistas à manutenção de sua supremacia. 
O sexto artigo, de António Manuel Magalhães, A Reconfiguração do Mandato Político Endereçado à Educação Superior Europeia, é uma análise sobre as implicaçôes educativas que as mudanças políticas, econômicas e sociais das últimas décadas têm vindo a promover na educação superior europeia. $\mathrm{O}$ autor defende que no contexto do desenvolvimento do Espaço Europeu do Ensino Superior o mandato endereçado à educação e às instituições de ensino superior tem se reconfigurado pelas articulaçóes entre 'educação', 'investigaçáo' e 'inovação' - o 'triângulo do conhecimento' difundido pela União Europeia. A partir da análise dessas articulações discursivas nos textos endossados pelos ministros europeus no âmbito do processo de Bolonha, o autor argumenta que, sob a hegemonia discursiva da 'inovação', é legitimado o mandato produtivista que modela a educação superior europeia.

O sétimo artigo, Industrialização da Educação, Edtech e Prática Docente, de Octavio Ribeiro de Mendonça Neto, Almir Martins Vieira e Maria Thereza Pompa Antunes, propóe uma reflexão sobre o processo de industrialização da educação nos tempos atuais, levando em conta a presença da educational technology (Edtech) como componente do cotidiano acadêmico-administrativo. $\mathrm{O}$ texto coloca em debate argumentos de pensadores que se posicionam a favor ou contra a industrialização da educação. O papel da Edtech também é tratado com projeçôes e estimativas de abrangência em termos de valor de mercado, além do aspecto da educação a distância (EAD), cenário no qual a Edtech assume papel crucial. No que diz respeito à prática docente, os autores afirmam que o processo de industrialização da educação exige das instituiçôes de ensino modelos de gestão baseados na calculabilidade e na busca pela eficiência que servem para vigiar, adestrar (dressage), controlar e avaliar o desempenho profissional.

No oitavo artigo, Americanismo, o novo marco de Ciência, Tecnologia e Inovação: sequestro do fundo público pelo capital financeiro, João dos Reis Silva Júnior, Fabíola Bouth Grello Kato e José Augusto Ewerton propóem uma análise sobre o contexto da financeirização da ciência produzida no Brasil, potencializada pelo novo Marco Legal de Ciência, Tecnologia e Inovação (Lei no 13.243/2016). As novas regras legais promovem a aproximação de instituições e centros científicos no intento de impulsionar o investimento em pesquisa. A análise feita pelos 
autores se concentra no entendimento das leis regulatórias referentes à CT\&I e na reflexão sobre a mercantilização do conhecimento produzida para abastecer a economia mundial.

Feito tal escrutínio, cabe esperar que tenhamos obtido êxito nos processos de seleção, avaliação e publicação dos artigos e que deem conta do tema do Dossiê. Nosso ânimo é o de apoiar professores e pesquisadores das áreas da Educação e das Ciências Sociais e Humanas em suas investigaçôes e reflexões, desse modo construindo os caminhos de contínua melhora da qualidade da produção científica e da atividade pedagógica docente nessas áreas.

\section{Seçáo Artigos}

A seção Artigos, que passamos a apresentar, é constituída a partir de demanda contínua não tematizada encaminhada a EccoS e, assim como os textos encaminhados ao Dossiê, devidamente avaliada por pares em processo de revisão cega. Nessa atual edição, essa seção é composta de catorze textos, que cabe apresentar ao leitor.

O primeiro, de Marcos Antônio Lorieri e Eduardo Gasperoni de Oliveira, tem por título Thauma e pensar bem na educação infantil". O texto é resultado de uma pesquisa sobre Filosofia e Educação para Pensar Bem na Educação Infantil, que teve como foco as possíveis contribuiçóes da proposta do Programa de Filosofia para Crianças - Educação para o Pensar, de Matthew Lipman, para o estabelecimento de procedimentos pedagógicos que favoreçam a manutençáo e o desenvolvimento da natural curiosidade das crianças em torno do conhecer. Os autores afirmam que, habitualmente, não há na Educação Infantil preocupação e procedimentos pedagógicos que potenciem a natural curiosidade manifestada pelas expressóes de admiração e de espanto (thauma, como o definiram Platão e Aristóteles) das crianças, curiosidade que é impulsionadora da busca de explicaçóes e entendimentos. A preocupação dos autores é responder à seguinte questão: Em que medida práticas reflexivas iniciais a partir das perguntas das crianças, de acordo com o proposto por Lipman, podem contribuir para uma educação para o pensar bem na Educação Infantil? 
Bolsa Permanência na UFMS: novas configuraçôes e velhos desafios, de Felipe Vieira Gimenez e Carina Elisabeth Maciel, é o segundo artigo da seção. O objetivo é analisar a percepção dos estudantes sobre a ação "Bolsa Permanência” na Universidade Federal de Mato Grosso do Sul/UFMS, campus Campo Grande, como estratégia para favorecer a permanência nos cursos de graduação presencial. É o resultado de uma pesquisa de caráter exploratório e de natureza bibliográfica e documental que apresenta como fontes relatórios e documentos institucionais do MEC e da UFMS para o período 2013-2015. Os resultados indicam que a Bolsa Permanência, vinculada à política de assistência estudantil na UFMS, constitui estratégia política que favorece, mas não garante, a permanência dos estudantes no campus universitário.

No terceiro artigo, Análise de politicas educacionais: a abordagem do ciclo de politicas e as contribuiçóes de Pierre Bourdieu, Rayane Regina Scheidt Gasparelo, Débora Cristina Jeffrey e Marisa Schneckenberg fazem uma análise do ciclo de política, articulando os fundamentos da abordagem proposta por Stephen Ball e Richard Bowe e as contribuiçóes conceituais de Pierre Bourdieu, para análise dos processos de formulação e implantação das políticas educacionais. É um estudo de natureza teórica que evidencia o movimento dialético entre os contextos de influência, de produção de texto e de prática na instauração de uma política pública, e a pertinência dos conceitos de habitus, campo e poder simbólico para analisar a articulação entre tais contextos. As autoras concluem que o processo de traduzir políticas em práticas constitui quase uma peça teatral, para a qual se propóe um roteiro, mas cuja realização ocorre quando os sujeitos a representam.

$O$ estado do conhecimento das pesquisas sobre formação de professores no quadro da expansão da educação superior no Brasil, de Bárbara Cristina Moreira Sicardi Nakayama e Douglas da Silva Tinti, é o quarto artigo. O objetivo é apresentar o estado do conhecimento das pesquisas brasileiras sobre projetos e programas desenvolvidos no contexto das políticas públicas de expansão da Educação Superior e que tratam especificamente da formação de professores. Os resultados desse trabalho indicam uma concentração de produção nas universidades públicas, apontam uma pluralidade de aportes teóricos utilizados e uma ênfase na utilização de metodologias de análise documental e estudos de caso. 
O quinto artigo, Professores na Educação de Jovens e Adultos: inserção, precarização e formação continuada, de Joana Celia Passos, apresenta reflexôes sobre a formaçáo continuada ofertada aos professores que atuam na Educação de Jovens e Adultos em uma Rede Municipal de Ensino, explorando suas interfaces com os processos de ingresso e de constituição da docência nessa modalidade educativa. A partir de uma análise documental e de entrevistas, os resultados principais da pesquisa evidenciam uma desvantagem da EJA no conjunto das políticas educacionais, dado que a concepção de provisoriedade dos gestores públicos não lhes permite assumir a educação como direito para jovens e adultos, o que se reflete na baixa institucionalização dessa modalidade nos sistemas de ensino.

O sexto artigo, Revolução passiva e o papel formativo da filosofia no Ensino Médio, de Paolo Nosella e Alessandra Maria Martins Gaidargi, é um estudo em desenvolvimento a partir do pensamento de Antonio Gramsci. Defendem os autores que a fecundidade teórica da categoria revolução passiva possibilita uma análise profunda e crítica da revolução midiática em curso. Partindo da definição do conceito gramsciano, os autores refletem sobre a revolução passiva na cultura brasileira em geral e, atualmente, sobre a indiscriminada e ampla utilização das mídias pelos jovens estudantes de ensino médio. Concluem com a defesa do ensino da filosofia na escola média como instrumento de reconstrução unitária e responsável da concepção de mundo pelos jovens adolescentes.

A formação do pedagogo na educação a distância: alguns dilemas e possibilidades, de Adriana Regina de Jesus Santos, José Alexandre Gonçalves e Rogério da Costa, é o sétimo artigo. Os objetivos do estudo foram compreender o perfil da formação do pedagogo e conhecer as diferenças de intencionalidade em relação a objetivos e perfil de egresso que os programas pretendem formar, tendo como parâmetro dois cursos de Pedagogia ofertados na modalidade de EaD, um de uma instituiçáo pública e outro de uma privada, localizadas na cidade de Telêmaco Borba, PR, bem como analisar as percepçôes dos acadêmicos em relação a sua formação, especificamente no que tange ao compromisso éticoprofissional. As conclusóes do estudo revelam a existência de uma certa ambiguidade no que se refere à formaçáo do perfil do pedagogo que se almeja formar, dado que na faculdade particular o foco estava voltado à empregabilidade desse profissional no mercado de trabalho e na institui- 
ção pública percebeu-se a preocupação com a formação ontológica, ética e política do futuro profissional pedagogo.

O oitavo artigo, Formação de professores universitários: novos paradigmas epistemológicos, outras práticas, de Evódio Mauricio Oliveira Ramos e Isabel Maria Sabino de Farias, analisa uma experiência formativa realizada em uma universidade pública baiana, apontando algumas contribuiçóes pedagógicas dessa formação na prática dos docentes participantes. Trata-se de um estudo qualitativo, do ponto de vista metodológico, considerando os autores que a formação se constituiu como um fórum de reflexão, espaço dialógico que possibilita ao docente universitário a ampliação de sua capacidade de ver, sentir, pensar, planejar, agir e avaliar sua ação pedagógica, dado o acesso propiciado a um novo paradigma epistêmico e metodológico pautado na dialogicidade, criticidade, contextualidade e protagonismo dos sujeitos envolvidos no processo educativo.

Tarcísio Luís Pereira e Sílvia Helena Andrade de Brito discutem, no nono artigo, A expansão da educação superior privada no Brasil por meio do FIES. Consideram os autores que o financiamento do governo federal foi importante tanto para a expansáo quanto para o crescimento dos grupos empresariais de educação superior privada no Brasil, entre a segunda metade dos anos 1990 à primeira década do século XXI. Analisam, ainda, como as açôes do governo federal, por meio do fundo público, vêm respondendo às demandas do setor privatista, e como este transforma a formação do indivíduo em mercadoria, que deve ser disponibilizada por meio de variadas formas, ampliando assim o acesso, por um lado, e também realizando seus lucros, por outro, como forma de consolidar os grandes grupos empresariais do setor.

O décimo artigo, $A$ interdisciplinaridade nas novas configuraçôes curriculares da educação superior brasileira: o caso dos BI da UFBA, de Gabriel Swahili Sales de Almeida, constitui uma discussão sobre os sentidos da interdisciplinaridade nos bacharelados interdisciplinares (BI) da Universidade Federal da Bahia a partir de uma pesquisa documental sobre o processo de criação desse formato de curso. Foram utilizados como fontes a legislação federal, resoluçóes e pareceres da UFBA e documentos de referência para os BI tais como seus projetos político-pedagógicos, compreendendo o período de 2006 a 2016. A partir da análise, o autor conclui que a ausência de uma política institucional especificamente voltada à in- 
terdisciplinaridade constituiu um fator limitante à afirmação dos BI como uma nova arquitetura acadêmica.

A educação superior em Santa Catarina: um século de história (19172017), de Sherlon Cristina De Bastiani, Joviles Vitório Trevisol e Ludimar Pegoraro, é o décimo primeiro artigo. Os autores apresentam, num estudo qualiquantitativo, os resultados de pesquisa sobre o processo de expansão/ interiorização da educação superior em Santa Catarina. Analisam a evolução da educação superior catarinense a partir de especificidades (contextos e realidades) locais e regionais. A pesquisa revela que a expansão em $\mathrm{SC}$ se deu por meio das fundaçôes educacionais de direito privado. $\mathrm{O}$ modelo fundacional foi hegemônico até os anos 2000, momento em que passa a ocorrer a expansão de IES públicas e de privadas com fins lucrativos, resultando, em 2015, no percentual de $88 \%$ de privadas com e sem fins lucrativos num total de 94 instituiçôes. A graduação a distância tem se expandido com altas taxas de crescimento, contudo, as matrículas em cursos presenciais de graduação ainda representam, em 2015, 72\% do universo de estudantes catarinenses.

Estudio de la creatividad de una perspectiva educativa en deficiencia visual, de Jose Enrique Llamazares Prado, Ana Rosa Arias Gago e Maria Antonia Melcon Alvarez, é o décimo segundo artigo, que salienta a importância da criatividade e do pensamento divergente na educação. $\mathrm{O}$ objetivo do texto é, sobretudo, a apresentação de uma revisão dos estudos sobre incapacidade visual e criatividade. Os autores evidenciam a função do potencial criativo, por meio do pensamento divergente, na criação de conceitos e ideias tendo em vista a resolução de problemas.

O décimo terceiro artigo, Revisão integrativa: letramentos do idoso e os círculos de cultura freirianos, de Daniel Aguiar Pereira, Eliane Feitoza Oliveira e Meire Cachioni, tem por objetivo traçar um panorama de como o letramento do idoso tem sido tratado em alguns artigos acadêmico-científicos, a fim de se entender as diferentes correntes teórico-metodológicas que embasam estudos sobre práticas escriturais da população idosa e como essas práticas impactam a vida dessa população. Analisam o letramento do idoso a partir do escopo teórico-metodológico dos novos estudos do letramento e do círculo de cultura freiriano. Consideram os autores que é necessário ampliar a compreensão sobre práticas de leitura e de escrita no contexto da Gerontologia, da Educação e da Linguística Aplicada, a 
fim de promover atividades que possibilitem ao idoso efetivar seus direitos básicos de cidadão.

Por fim, o último artigo, A Teoria do Agir Comunicativo e a Formação Médica: Análise Critica das Competências Curriculares e da Relação MédicoPaciente, de Antonio da Silva Menezes Junior e Iria Brzezinski, é o resultado de uma pesquisa qualitativa que tem como fundamento teórico a teoria do agir comunicativo de Habermas. Os autores consideram que as políticas instituídas reproduzem o modelo neoliberal quando não agregam a possibilidade de inclusão do outro e não estabelecem a possibilidade do diálogo como processo de (re) construção das relaçôes humanas, em especial da relação médico-paciente e do trabalho em equipe multiprofissional.

Encerrada a apresentação desta seção de EccoS, assim como nos referimos à seção Dossiê, esperamos contribuir, com a diversidade e abrangência das temáticas aqui tratadas por pesquisadores ativos da pós-graduação brasileira, para as investigações científicas nas áreas da Educação, especialmente, e para as áreas de Ciências Sociais e Humanas.

A todos uma boa leitura!

Os Editores Eduardo Santos Manuel Tavares 